\title{
Urea/thiourea induced crystal growth of ammonium nickel sulfate hexahydrate and characterization studies
}

\author{
K. Meena $\cdot$ K. Muthu $\cdot$ M. Rajasekar $\cdot$ \\ G. Bhagavannarayana $\cdot$ S. P. Meenakshisundaram • \\ S. C. Mojumdar
}

Received: 8 June 2014 / Accepted: 14 October 2014/Published online: 7 November 2014

(c) Akadémiai Kiadó, Budapest, Hungary 2014

\begin{abstract}
Single crystals of ammonium nickel sulfate hexahydrate, $\left(\mathrm{NH}_{4}\right)_{2} \mathrm{Ni}\left(\mathrm{SO}_{4}\right)_{2} \cdot 6 \mathrm{H}_{2} \mathrm{O}(\mathrm{ANSH})$, are grown by conventional slow evaporation solution growth technique at room temperature from an aqueous solution containing an excess of urea/thiourea. Structural analysis by single crystal X-ray diffraction analysis reveals that the crystal belongs to monoclinic system with centrosymmetric space group $P 2_{1} / c$ and the cell parameters are $a=6.246(2) \AA$, $b=12.45(4) \AA, c=9.21(2) \AA, \beta=106.96^{\circ}$. The powder $\mathrm{X}$-ray diffraction and high-resolution $\mathrm{X}$-ray diffraction studies reveal the crystallinity and crystalline perfection of the grown crystal. Optical absorbance spectrum indicates a discontinuous transmission pattern. An increase in dielectric and conductivity parameters with the increase of temperature at all frequencies is observed. Thermal studies reveal that there is no decomposition up to the melting point. Probable mechanism of facile crystal growth of the
\end{abstract}

K. Meena $\cdot$ K. Muthu $\cdot$ M. Rajasekar .

S. P. Meenakshisundaram

Department of Chemistry, Annamalai University,

Annamalainagar 608 002, India

G. Bhagavannarayana

Crystal Growth \& X-ray Analysis Activity, CSIR-NPL,

New Delhi 110 012, India

S. C. Mojumdar $(\square)$

Department of Chemical Technologies and Environment, Faculty of Industrial Technologies, Trenčín University

of A. Dubček, 02032 Púchov, Slovakia

e-mail: scmojumdar@yahoo.com

S. C. Mojumdar

Department of Chemistry, University of Guelph,

Guelph, ON, Canada

e-mail: subhash.mojumdar@utoronto.ca title compound in the presence of excess urea/thiourea as inducer is analyzed.

Keywords Crystal growth - High-resolution X-ray diffraction - Thermal analysis · UV-filter - Dielectric studies $\cdot$ ANSH

\section{Introduction}

Ultraviolet light filters, usually made of optical crystals, allow UV light to be selectively transmitted and have been applied in various devices [1]. Most of the crystals show continual optical transmission from UV to near IR wavelengths range and few of them show discontinuity in the above-mentioned range. UV filters are used in missile approach warning systems which locate and track sources of ultra-violet energy, enabling the system to distinguish the plume of an incoming missile from other UV sources that pose no threat. The success and efficiency of the system for helicopters or transport-type aircrafts depend on the UV sensors [2]. Potassium manganese nickel sulfate hexahydrate [2], potassium nickel sulfate hexahydrate [3], cesium nickel sulfate hexahydrate [4], iron nickel sulfate twelve hydrate [5], rubidium nickel sulfate hexahydrate [6], ammonium cobalt nickel sulfate hexahydrate [7], and ammonium nickel sulfate hexahydrate [8] have been reported as UV filter materials. Growth of ammonium nickel sulfate hexahydrate (ANSH) of dimension $20.5 \times 28 \times 15 \mathrm{~mm}$ from an aqueous solution containing equimolar proportions of ammonium sulfate and nickel sulfate hexahydrate at $80{ }^{\circ} \mathrm{C}$ and its structure have been reported $[8,9]$. Bulk growth by gel technique was also reported [10]. Our attempts to grow good quality bulk and transparent crystals of ANSH from its aqueous solution by 
slow evaporation solution growth technique are not successful. Interestingly, excess of urea/thiourea in the aqueous growth medium facilitates the crystal growth process of ANSH. The aims of this work are the systematic studies of ANSH. In this article, we report the bulk growth of ammonium nickel sulfate hexahydrate in the presence of urea/thiourea as inducer and the probable mechanistic aspects. Thermal, spectral, structural, and optical studies are very important techniques in the characterization of various materials [11-33]. The as-grown crystal is characterized by FT-IR, X-ray diffraction (XRD), high-resolution X-ray diffraction (HRXRD), UV-Vis, thermal, and dielectric studies.

\section{Experimental}

Crystal growth

An aqueous solution of ANSH and urea/thiourea (1:2) was stirred for 3-4 h at room temperature to obtain a homogeneous solution. A small portion of the mother solution was used to get seed crystals by slow evaporation of the solvent. The crystallization took place within 18-20 days. Macroscopic defect-free seed crystals of ANSH were harvested, and one such seed was used for bulk crystal growth. The photographs of the as-grown ANSH crystals are shown in Fig. 1.

Close observation of solubility data (Table 1) reveals that the induced crystallization is due to largely varied solubilities of urea/thiourea and ammonium nickel(II) sulfate hexahydrate. Less soluble ANSH is thrown out from the aqueous solution during the slow evaporation since there is less free water available to dissolve the ammonium salt. 'Salting out' could be the prime reason for the induced

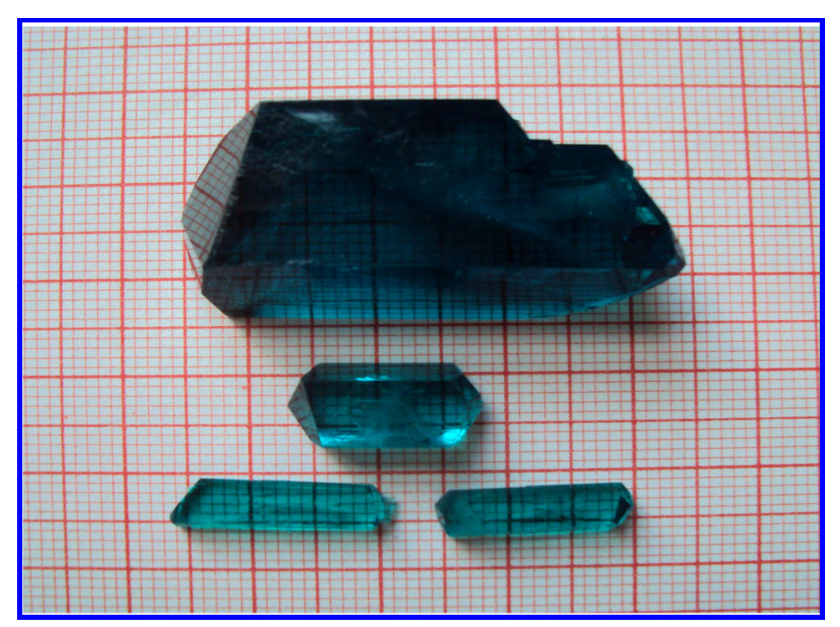

Fig. 1 Photographs of as-grown ANSH crystals
Table 1 Solubility data of ANSH, urea and thiourea at $20^{\circ} \mathrm{C}$

\begin{tabular}{lc}
\hline Materials & Solubility/g L \\
\hline ANSH & $\sim 25$ \\
Urea & $\sim 1,080$ \\
Thiourea & $\sim 137$ \\
\hline
\end{tabular}

facile crystal growth in the presence of excess urea/ thiourea.

\section{Characterization techniques}

The FT-IR spectrum was recorded on an AVATAR 330 FT-IR by $\mathrm{KBr}$ pellet techniques in the range 4,000-400 $\mathrm{cm}^{-1}$. Bruker AXS (Kappa APEXII) X-ray diffractometer with graphite monochromated Mo $\mathrm{K} \alpha$ radiation $(\lambda=0.71073 \AA$ ) was used to analyze the lattice parameters of ANSH. The powder XRD pattern of ANSH is recorded using Philips X'pert Pro Triple-axis X-ray diffractometer at room temperature using a wavelength of $1.540 \AA$ and a step size of $0.008^{\circ}$. Optical absorption spectrum was recorded in the wavelength region from 200 to $900 \mathrm{~nm}$ on a Perkin-Elmer Lambda $35 \mathrm{UV}-\mathrm{Vis}$ spectrophotometer. The TG-DSC analysis of ANSH was carried out at $20-800{ }^{\circ} \mathrm{C}$ in the nitrogen atmosphere on a NETZSCH STA $409 \mathrm{C}$ thermal analyzer, at a heating rate of $10{ }^{\circ} \mathrm{C} \mathrm{min}{ }^{-1} .0 .5 \mathrm{~g}$ of sample taken in an $\mathrm{Al}_{2} \mathrm{O}_{3}$ crucible is placed on top of a thermocouple resting on a balance and the system is sealed into a chamber and heated with a constant heating rate. Dielectric measurements were carried out by the parallel plate capacitor method as a function of temperature for various frequencies using a precision LCR meter (AGILENT 4284 A model).

The crystalline perfection of the specimen was characterized by HRXRD by employing a multicrystal X-ray diffractometer developed at NPL [34]. The well collimated and monochromated Mo $\mathrm{K} \alpha_{1}$ beam obtained from the three monochromator $\mathrm{Si}$ crystals set in dispersive $(+,-,-)$ configuration has been used as the exploring X-ray beam. The rocking or diffraction curves (DC) were recorded by changing the glancing angle (angle between the incident X-ray beam and the surface of the specimen) around the Bragg diffraction peak position $\theta_{\mathrm{B}}$ (taken as zero for the sake of convenience) starting from a suitable arbitrary glancing angle and ending at a glancing angle after the peak so that all the meaningful scattered intensities on both sides of the peak include in the diffraction curve. Before recording the diffraction curve to remove the non-crystallized solute atoms remained on the surface of the crystal and the possible layers which may sometimes form on the surfaces on crystals grown by solution methods [35, 36] and also to ensure the surface planarity, the specimen was 
first lapped and chemically etched in a non-preferential etchant of water and acetone mixture in 1:2 volume ratio.

\section{Results and discussion}

\section{FT-IR spectrum}

Figure 2 shows the FT-IR spectrum recorded for the sample on an AVATAR 330 FTIR by KBr pellet technique in the range of $400-4,000 \mathrm{~cm}^{-1}$. The broad absorption band centered around $3,258 \mathrm{~cm}^{-1}$ can be attributed to $\mathrm{OH}^{-}$ vibration mode. The peak centered around $1,150 \mathrm{~cm}^{-1}$ is due to $\mathrm{S}=\mathrm{O}$ stretching frequency of sulfate ion. The characteristic of the urea/thiourea vibrational patterns is absent, ruling out any type of interaction between the host crystal and inducer.

\section{Single crystal X-ray diffraction}

The as-grown ANSH crystal was subjected to single crystal $\mathrm{X}$-ray diffraction analysis to determine unit cell dimensions. It belongs to monoclinic system with centrosymmetric space group $P 2_{1} / c$. The obtained unit cell parameters, $a=$ 6.246(2) $\AA, b=12.45(4) \AA, c=9.21(2) \AA, \beta=106.96$ are in good agreement with the reported values $[8,9]$. This clearly establishes the fact that the product formed is only ANSH and urea/thiourea is not reacting with it.

Powder X-ray diffraction

Figure 3 shows the indexed powder XRD pattern of ANSH. The samples were examined with $\mathrm{Cu} \mathrm{K}_{\alpha}$ radiation in a $2 \theta$ range of $10^{\circ}-80^{\circ}$. The well-defined Bragg's peaks at specific $2 \theta$ angles show good crystallinity of the material. The characteristic peaks are in good agreement with the JCPDS file [37].

High-resolution X-ray diffraction

Figure 4 shows the high-resolution X-ray diffraction curve recorded for (210) diffraction planes for ANSH. The curve does not seem to be a single peak and it contains an additional peak which is 412 arc sec away from the higher intensity peak. For more details of such structural grain boundaries including their effect on physical properties, reference is made available elsewhere [38, 39]. The full

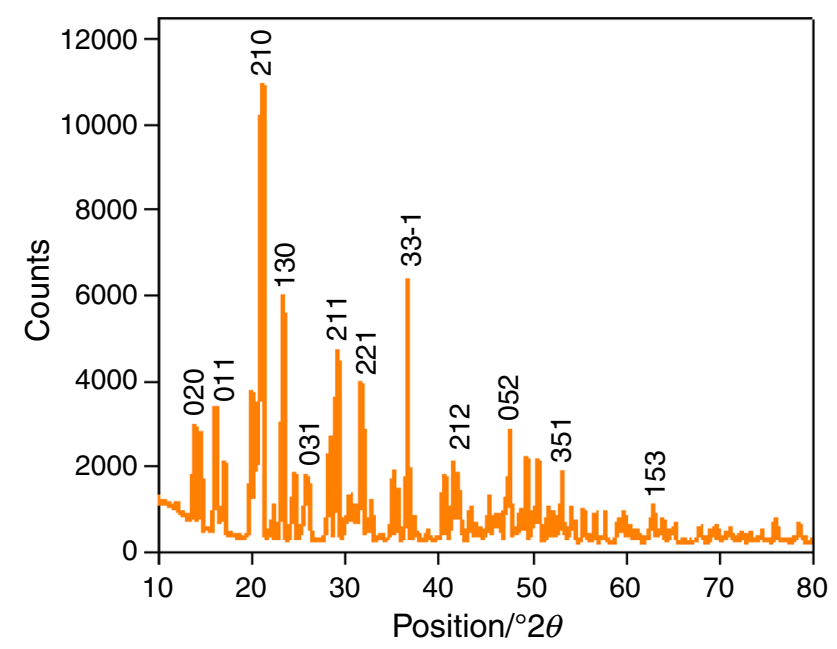

Fig. 3 Powder X-ray diffraction pattern of ANSH crystal
Fig. 2 FT-IR spectrum of ANSH crystal

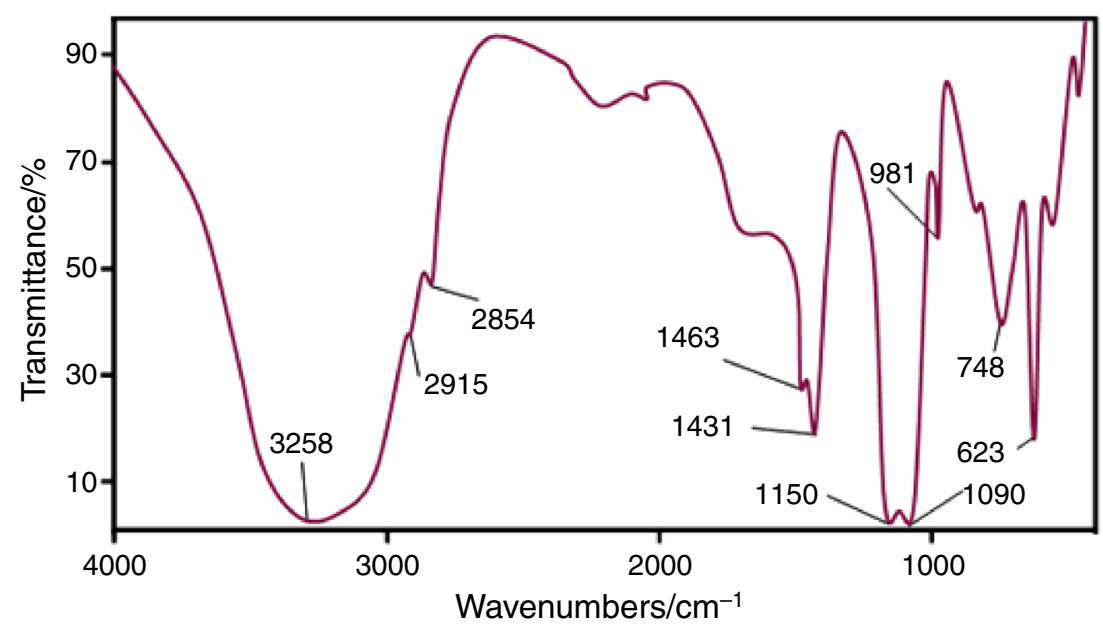




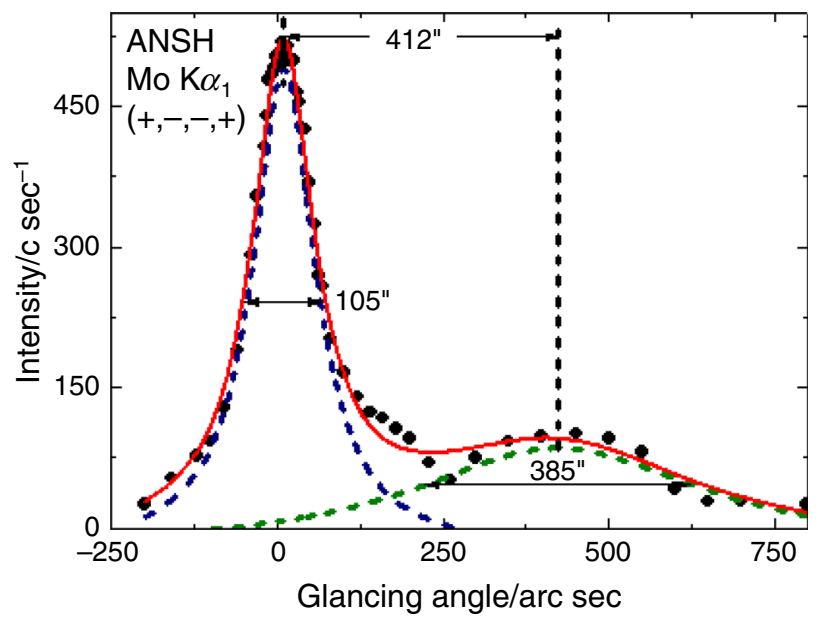

Fig. 4 HRXRD curve recorded for ANSH crystal

width at half maximum (FWHM) of the main peak and the low-angle boundary are 105 and 385 arc sec, respectively. These relatively low values reveal the fact that both the regions of the crystal are nearly perfect. These types of structural defects are probably generated in the crystals due to mechanical/thermal fluctuations occurred during the growth process and/or also due to fast growth [40].

Optical studies

Optical absorption spectrum of ANSH was recorded in the wavelength region from 200 to $900 \mathrm{~nm}$ on a Perkin-Elmer Lambda $35 \mathrm{UV}-\mathrm{Vis}$ spectrophotometer. The as-grown specimen was polished, and the good transparent single crystal with $2 \mathrm{~mm}$ thickness was used for the optical studies. Figure 5 shows that the absorption is discontinuous in the visible region and IR as reported earlier [8, 41].

Thermal analysis

The TG-DSC analysis of ANSH was carried out in the nitrogen atmosphere, and the TG-DSC curves are given in Fig. 6. The TG curve illustrates that the compound is thermally stable up to $100{ }^{\circ} \mathrm{C}$ and the mass loss started above $100{ }^{\circ} \mathrm{C}$ due to dehydration and decomposition of ANSH into fragments and its subsequent volatilization. TG curve exhibits total four mass loss steps in $100-200{ }^{\circ} \mathrm{C}$, 200-420 ${ }^{\circ} \mathrm{C}, 420-550{ }^{\circ} \mathrm{C}$, and $550-750{ }^{\circ} \mathrm{C}$ corresponding to the dehydration and decomposition of ANSH into fragments. We observe a slightly higher dehydration temperature of ANSH $\left(\sim 100{ }^{\circ} \mathrm{C}\right)$ in comparison with the melting temperatures reported earlier $[8,41]$. In DSC, a sharp endothermic peak at $\sim 165{ }^{\circ} \mathrm{C}$ could be due to the decomposition of the material and it is matching with the major mass loss on TG curve. The sharpness of the

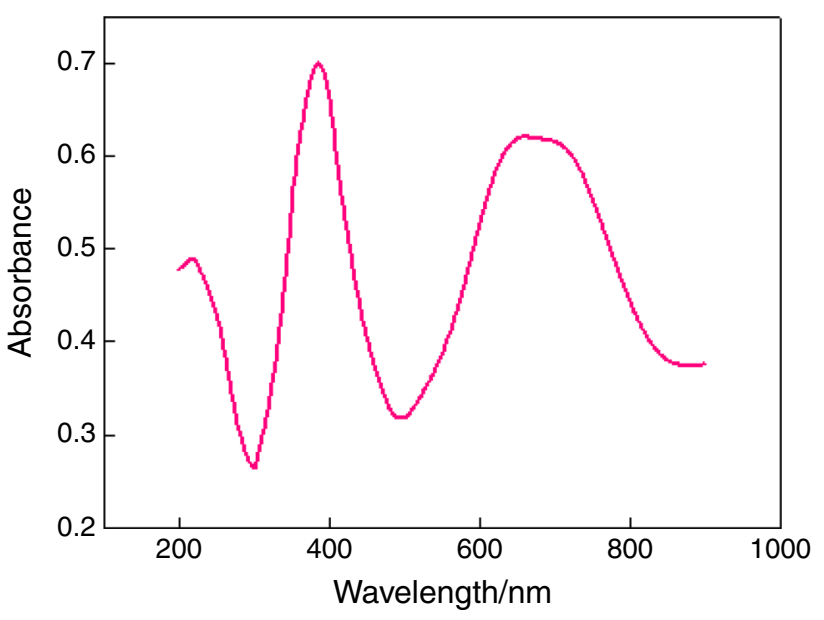

Fig. 5 UV-Vis spectrum of ANSH crystal

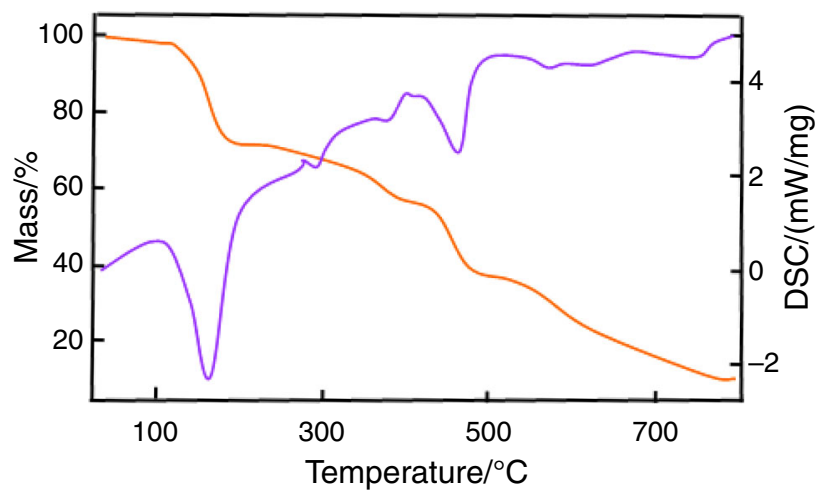

Fig. 6 TG-DSC curves of ANSH crystal

endothermic peak shows a good degree of crystallinity and purity. The gradual mass loss on TG curve observed between 165 and $800{ }^{\circ} \mathrm{C}$ is due to the liberation of volatile substances like ammonia, nitric oxide, sulfur dioxide etc.

Dielectric studies

Dielectric measurements (Fig. 7a-c) were carried out by the parallel plate capacitor method as a function of temperature for various frequencies. It can be seen that dielectric parameters are temperature dependent. It is observed that $\varepsilon_{\mathrm{r}}$ and $\tan \delta$ both are inversely proportional to frequency. The decreased dielectric constant at higher frequencies could be due to the reduction in the space charge polarization. Dielectric constant varying proportionally with temperature could be due to the temperature variation of the polarizability [42]. The characteristic low dielectric loss with high frequency indicates that the asgrown crystal has good optical quality with lesser defects, and the low $\varepsilon_{\mathrm{r}}$ value dielectric materials have potential applications in microelectronic industries. 

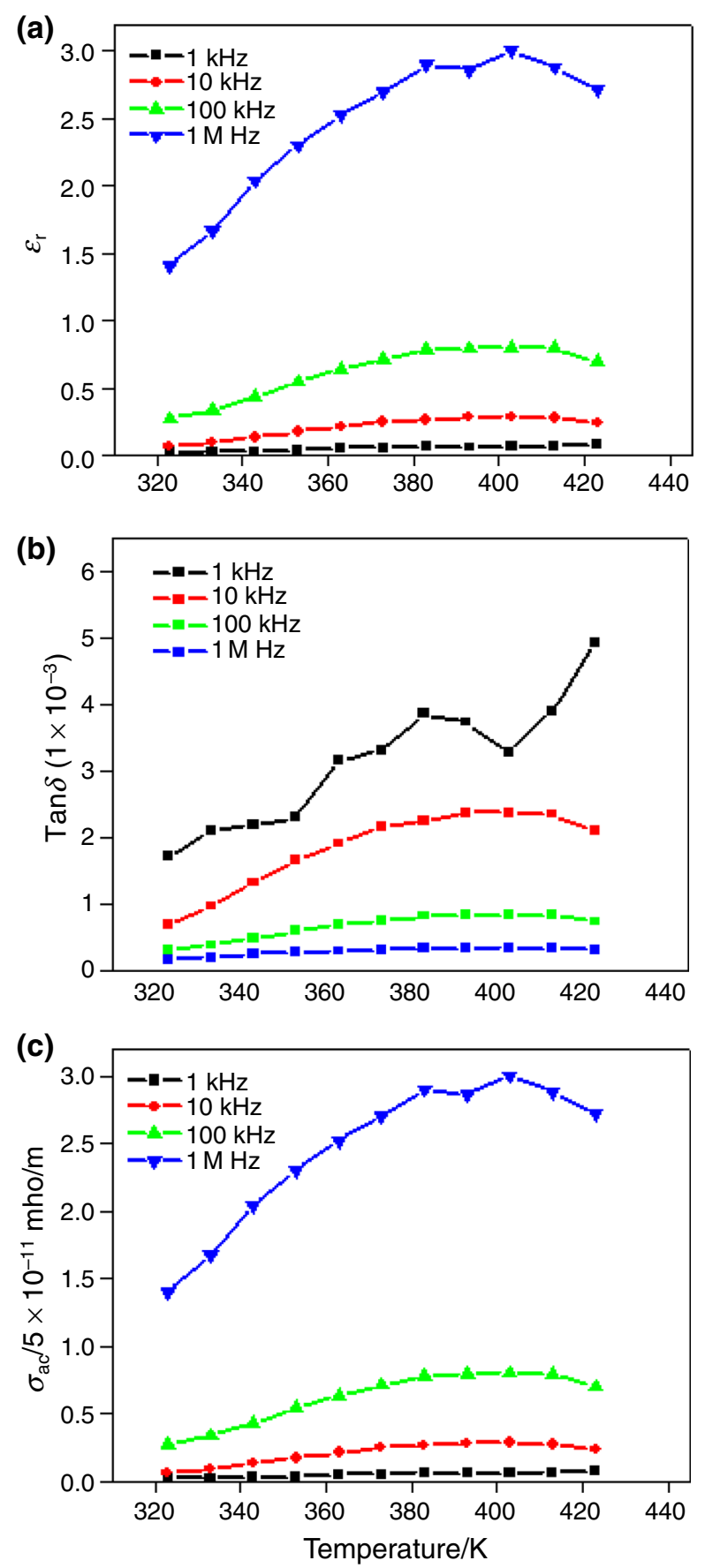

Fig. 7 Dielectric measurements for ANSH crystal. a Plot of dielectric constant versus temperature, b plot of dielectric loss versus temperature, and $\mathbf{c}$ plot of $\mathrm{AC}$ electrical conductivity versus temperature

\section{Conclusions}

We have developed a successful method of bulk growth, and transparent dark green crystals of ammonium nickel sulfate hexahydrate of dimension $\sim 39 \times 18 \times 12 \mathrm{~mm}^{3}$ were grown with ease by slow evaporation solution growth technique at room temperature in the presence of excess urea/thiourea, inducing the crystallization process. Narrow peaks in powder X-ray diffraction study reveal good crystallinity of the material and the additional peaks in HRXRD indicate the formation of low angle structural grain boundaries. The crystal has a good thermal stability, a required property in device applications and a discontinuous transmittance pattern. The low dielectric constant at high frequency is indicative of a less defective good quality optical crystal. Relative ease of crystal growth of ammonium salt in the presence of excess urea/thiourea is rationalized by 'salting out' process, quite a possibility because of large difference in solubility between the ammonium salt and inducer.

Acknowledgements The authors thank Dr. C. K. Mahadevan, Physics Research Centre, S. T. Hindu College, Nagercoil for the support in dielectric studies. One of the authors, K. Muthu is thankful to CSIR, New Delhi, for the award (no. 9/3(0009)2K11-EMR-I) of a Senior Research Fellowship.

\section{References}

1. Singh NB and Partlow WD. Crystals for ultraviolet light filters. US Patent No. 5778765.

2. Duraikkan V, Bahadur SA, Athimoolam S. Crystal growth and characterization of potassium manganese nickel sulfate hexahydrate: a new uv filter. J Miner Mater Charact Eng. 2012;11: 1121-5.

3. He Y, Chen J, Su G, Zhuang X, Lee G, Jiang R. Growth of potassium nickel sulfate hexahydrate $(\mathrm{KNSH})$ crystal and its characterization. J Cryst Growth. 2001;233:809-12.

4. Rudneva EB, Manomenova VL, Malakhova LF, Voloshin AE, Smirnova TN. $\mathrm{Cs}_{2} \mathrm{Ni}\left(\mathrm{SO}_{4}\right)_{2} \cdot 6 \mathrm{H}_{2} \mathrm{O}(\mathrm{CNSH})$ crystal: growth and some properties. Crystallogr Rep. 2006;51:344-7.

5. Su G, Zhuang XX, He YP, Li ZD, Wang GF, Li GH, Huang ZX. A new single crystal of iron nickel sulfate twelve hydrate (FNSH) used as optical band pass filters. J Cryst Growth. 2002;243: 238-42.

6. Wang X, Zhuang XX, Su GB, He YP. A new ultraviolet filter: $\mathrm{Rb} 2 \mathrm{Ni}\left(\mathrm{SO}_{4}\right)_{2} \cdot 6 \mathrm{H}_{2} \mathrm{O}(\mathrm{RNSH})$ single crystal. Opt Mater. 2008;31: 233-6.

7. Su G, Zhuang X, He Y, Zheng G. A new crystal of ammonium cobalt nickel sulfate hexahydrate for UV light band-pass filter. J Cryst Growth. 2008;30:906-19.

8. Su G, Zhuang X, He Y, Li Z, Wang G. Ammonium nickel sulfate crystal: a new ultraviolet light filter. J Phys D. 2002;35:2652-5.

9. Grimes NW, Kay HF, Webb MW. The crystal structure of ammonium nickel sulfate hexahydrate $\left(\mathrm{NH}_{4}\right)_{2} \mathrm{Ni}\left(\mathrm{SO}_{4}\right)_{2} \cdot 6 \mathrm{H}_{2} \mathrm{O}$. Acta Crystallogr. 1963;16:823-9.

10. Baviskar SJ, Bhavsar DS. Growth and characterization of ammonium nickel sulfate grown by gel technique. Arch Appl Sci Res. 2011;3:279-84.

11. Vasudevan G, Anbusrinivasan P, Madhurambal G, Mojumdar SC. Thermal analysis effect of dopants spectral characterization and growth aspect of KAP crystals. J Therm Anal Calorim. 2009;96:99-102.

12. Anbusrinivasan P, Madhurambal G, Mojumdar SC. Thermal and spectral properties and induction period, intrafacial energy and nucleation parameters of solution grown anthracene. J Therm Anal Calorim. 2012;108:939-46. 
13. Ramalingam S, Anbusrinivasan P, Periandy S. FT-IR and FTRaman spectral investigation, computed IR-intensity and Raman activity analysis and frequency estimation analysis on 4-chloro-2bromoacetophenone was-HF and DFT calculations. Spectrochim Acta Part A. 2011;78:826-34.

14. Mojumdar SC, Raki L. Preparation, thermal, spectral and microscopic studies of calcium silicate hydrate poly(acrylic acid) nanocomposite materials. J Therm Anal Calorim. 2006;85:99105.

15. Ezhilvizhi R, Kalainathan S, Bhavannarayana G. Structural and micro hardness studies of urea and thiourea doped glycine phosphate single crystal. Cryst Rev Technol. 2008;43:778-82.

16. Mojumdar SC. Processing moisture resistance and thermal analysis of MDF material. J Therm Anal Calorim. 2001;64:1133-9.

17. Madhurambal G, Ramasamy P, Anbusrinivasan P, Vasudevan G, Kavitha S, Mojumdar SC. Growth and characterization studies of 2-bromo-4" -chloro-acetophenone (BCAP) crystals. J Therm Anal Calorim. 2008;94:59-62.

18. Mojumdar SC. Thermal properties, environmental deterioration and application of macro-defect-free cements. Res J Chem Environ. 2005;9:23-7.

19. Madhurambal G, Mojumdar SC, Hariharan S, Ramasamy P. TG, DTC, FT-IR and Raman spectral analysis of ZNIMg, ammonium sulfate mixed crystals. J Therm Anal Calorim. 2004;78:125-33.

20. Selvaraju K, Valluvan R, Kumararaman S. A new metal organic potassium thiourea chloride single crystal. Mat Lett. 2006;440: 574-81.

21. Sawant SY, Verenkar VMS, Mojumdar SC. Preparation, thermal, XRD, chemical and FT-IR spectral analysis of $\mathrm{NiMn}_{2} \mathrm{O}_{4}$ nanoparticles and respective precursor. $\mathrm{J}$ Therm Anal Calorim. 2007;90:669-72.

22. Porob RA, Khan SZ, Mojumdar SC, Verankar VMS. Synthesis, TG, SDC and infra-red spectral study of $\mathrm{NiMn}_{2}\left(\mathrm{C}_{2} \mathrm{H}_{4} \mathrm{O}_{4}\right)_{3} 6 \mathrm{~N}_{2} \mathrm{H}_{4}$ : a precursor for $\mathrm{NiMn}_{2} \mathrm{O}_{4}$ nanoparticles. J Therm Anal Calorim. 2006;86:605-8.

23. Mojumdar SC, Varshney KG, Agarval A. Hybrid fibrous ion exchange materials past-prevent and failure. Res J Chem Environ. 2006;10:89-103.

24. Doval M, Palou M, Mojumdar SC. Hydration behavior of $\mathrm{C}_{2} \mathrm{~S}$ and $\mathrm{C}_{2} \mathrm{~A}_{\mathrm{S}}$ nanomaterial synthesized by sol-gel method. $\mathrm{J}$ Therm Anal Calorim. 2006;86:595-9.

25. Varshney G, Agarwal A, Mojumdar SC. Pyridine based cerium(IV) phosphate hybrid fibrous ion exchanger synthesis characterization and thermal behavior. $\mathrm{J}$ Therm Anal Calorim. 2007;90:731-4.

26. Mojumdar SC, Melinik M, Jona E. Thermal and spectral properties of $\mathrm{Mg}(\mathrm{II})$ and $\mathrm{CU}(\mathrm{II})$ complexes with heterocyclic N-donor ligands. J Anal Appl Pyrolysis. 2000;53:149-60.

27. Mojumdar SC, Sain M, Prasad RC, Sun L, Venart JES. Selected thermoanalytical methods and their applications from medicine to construction. J Therm Anal Calorim. 2007;60:653-62.
28. Mojumdar SC, Simon P, Krutosikova A. Benzofuro 3, 2-c pyridine synthesis and coordination reactions. J Therm Anal Calorim. 2009;96:103-9.

29. Mojumdar SC, Miklovic J, Krutosikova A, Valigura D, Stewart JM. Furopyridine-Ni(II) complexes-synthesis, thermal and spectral characterization. J Therm Anal Calorim. 2005;81:211-5.

30. Mojumdar SC. Thermoanalytical and IR spectroscopy investigation of $\mathrm{Mg}(\mathrm{II})$ complexes with hetrocyclic ligands. J Therm Anal Calorim. 2001;64:629-36.

31. Narayanamoolaya B, Dharmaprakash SM. Synthesis, growth and characterization of nonlinear optical crystal L-tyrosine hydro bromide. J Cryst Growth. 2006;290:498-503.

32. Jayalakshmi D, Kumar J. Growth and characterization of bisthiourea zinc acetate. Cryst Res Technol. 2006;41:37-40.

33. Mojumdar SC, Mazanec K, Drabik M. Macro detect free (MDF) cements; synthesis, thermal, chemical, SEM and magnetometric study and moisture resistance. J Therm Anal Calorim. 2006; 83:135-9.

34. Lal K, Bhagavannarayana G. A high-resolution diffuse X-ray scattering study of defects in dislocation-free silicon crystals growth by the float-zone method and comparison with Czochralski-grown crystals. J Appl Cryst. 1989;22:209-15.

35. Muthu K, Bhagavannarayana G, Meenakshisundaram SP. Synthesis, growth, structure and characterization of nickel(II)-doped hexaaquacobalt(II) dipotassium tetrahydrogen tetra- $O$-phthalate tetrahydrate crystals. Solid State Sci. 2012;14:1355-60.

36. Bhagavannarayana G, Parthiban S, Meenakshisundaram S. Enhancement of crystalline perfection by organic dopants in ZTS, ADP and KHP crystals as investigated by high-resolution XRD and SEM. J Appl Cryst. 2006;39:784-90.

37. JCPDS file no. : 72-0505.

38. Bhagavannarayana G, Kushwaha SK. Enhancement of SHG efficiency by urea doping in ZTS single crystals and its correlation with crystalline perfection as revealed by Kurtz powder and high-resolution X-ray diffraction methods. J Appl Cryst. 2010;43:154-62.

39. Bhagavannarayana G, Ananthamurthy RV, Budakoti GC, Kumar B, Bartwal KS. A study of the effect of annealing on Fe-doped $\mathrm{LiNbO}_{3}$ by HRXRD, XRT and FT-IR. J Appl Cryst. 2005;38: 768-71.

40. Bhagavannarayana G, Rajesh P, Ramasamy P. Interesting growth features in potassium dihydrogen phosphate: unravelling the origin and dynamics of point defects in single crystals. J Appl Cryst. 2010;43:1372-6.

41. Su G, Zhuang X, He Y, Zheng G. A new crystal of ammonium cobalt nickel sulfate hexahydrate for UV light band-pase filter. Opt Mater. 2008;30:916-9.

42. Priya M, Mahadevan CK. Preparation and dielectric properties of oxide added $\mathrm{NaCl}-\mathrm{KCl}$ polycrystals. Phys B. 2008;403:67-74. 